\title{
PERGAMON
}

www.elsevier.com/locate/watres

\section{MODIFIED INORGANIC POLYMER FLOCCULANT-PFSi: ITS PREPARATION, CHARACTERIZATION AND COAGULATION BEHAVIOR}

\author{
DONGSHENG WANG and HONGXIAO TANG* \\ State Key Laboratory of Environment Aquatic Chemistry, Research Centre for Eco-Envir. Sci., \\ Academia Sinica, P.O. Box 2871, Beijing 100085, People's Republic of China
}

(First received 7 April 2000; accepted in revised form 27 December 2000)

\begin{abstract}
As a new kind of water and wastewater treatment reagents, inorganic polymer flocculants (IPFs) are in a trend of rapid development. Among them, iron-based IPF without any toxic problems is greatly expected. In this paper, a new protocol for preparation of iron-based IPF is investigated. Three kinds of silica, named silicaA, silicaB and silicaC, are prepared and used as modifiers to tailor-make polyferric silicate (PFSi), denoted PFSiA, PFSiB and PFSiC, respectively, in accordance to the above silica. Based on several direct and indirect speciation methods, the species distribution and characteristic of three kinds of PFSi are investigated in detail. The experiment results show that the species distribution of PFSi is mainly decided by the kinds of silica introduced and $\mathrm{Si} / \mathrm{Fe}$ ratio adopted. SilicaA and silicaB function as precipitation preventing reagents during the hydrolysis of $\mathrm{Fe}(\mathrm{III})$. At certain amount of basicity, $\mathrm{Fe}_{\mathrm{a}}$ (monomers) increases with increase of $\mathrm{Si} / \mathrm{Fe}$ ratio, while $\mathrm{Fe}_{\mathrm{c}}$ (colloidal species) decreases markedly. Although the formation of $\mathrm{Fe}_{\mathrm{c}}$ is inhibited, the stabilization of $\mathrm{Fe}_{\mathrm{b}}$ (oligomers or polymers) can still not be achieved. SilicaC on the other hand exhibits little effect on the species distribution of modified $\mathrm{Fe}(\mathrm{III})$ solutions. The coagulation behavior of above PFSi is also examined. The different effect of silica is then discussed with respect to the chemical species. (C) 2001 Elsevier Science Ltd. All rights reserved
\end{abstract}

Key words—coagulation, inorganic polymer flocculant (IPF), Fe(III), modifier, silica

\section{INTRODUCTION}

Inorganic polymer flocculants (IPFs) are a new kind of water and wastewater treatment reagents, which have been developed worldwide since the 1960s (Tang and Stumm, 1987; Tang, 1990). Because of their superior efficiency and relatively lower cost compared with traditional coagulants such as aluminum or iron salts, IPFs are becoming the main water and wastewater treatment reagents, with production and applications on a large scale in Japan, Russia, West Europe and China presently. The USA has also paid much attention to it in recent years (Tang, 1990; AWWA, 1989; Dentel, 1991; Gray et al., 1995).

Being tailor-made to contain desired more powerful coagulating species, pre-produced IPFs are successful in surpassing the effectiveness of inorganic metal salts and in remedying certain difficulties experienced with seasonal changes in surface water quality (Tang and Stumm, 1987; Gray et al., 1995; Bottero, 1990; Dempsey et al., 1984; Van Benschoten and Edzwald, 1990a,b). Since the application of aluminum-based coagulants was questioned for their potential toxicity (Lewis, 1989), the needs of iron-

*Author to whom all correspondence should be addressed. Fax: +86-10-6292-3563; e-mail: wgds@mail.rcees.ac.cn based coagulants both on their quality and quantity are increased. However, compared with aluminumbased IPFs, they are still in the development stage and remain in laboratory tests. Although there is commercial polyferric sulfate (PFS) product available, which is manufactured by utilization of industrial wastes or byproducts and therefore at a lower cost, its efficiency remains in a common level. While PFS has been produced in a limited extent, polyferric chloride ( $\mathrm{PFCl})$ is still in a state of controversy (Tang and Stumm, 1987; Mikami et al., 1980). LePrince et al. (1984) reported the partially neutralized iron(III) chloride prepared at $r_{\mathrm{OH}}(=\mathrm{OH} /$ $\mathrm{Fe}) 2.5$ exhibited the best capability for turbidity removal, especially at low temperatures. Tang and Stumm after detailed examination of $\mathrm{PFCl}$ solutions at various $B^{*}\left(=\mathrm{OH}_{\text {bound }} / \mathrm{Fe}_{\text {total }}\right)$ values, classified $\mathrm{PFCl}$ into five types and considered the type $\mathrm{C}$ at the intermediate $B^{*}$ values to contain the largest portion of high charged polycations (Tang and Stumm, 1987). Recently, Tang et al. (1994) improved markedly the stability and efficiency of $\mathrm{PFCl}$ by using phosphate as stabilizer.

In this investigation, we tried to prepare iron-based IPF-PFSi by adding other modifiers of several kinds of silica. The species distribution and transformation properties were characterized by combining direct 
and indirect speciation methods. The coagulation behavior of preformed PFSi was then examined and discussed in respect of different chemical species.

\section{BACKGROUND OF MODIFIER SELECTION}

In aqueous solution, the trivalent $\mathrm{Fe}(\mathrm{III})$ ions readily undergo hydrolysis, complexation/polymerization and precipitation. In general, the $\mathrm{Fe}(\mathrm{III})$ monomers and polymers generated by hydrolysis have a stronger tendency to precipitation than aluminum. How to stabilize the iron polymers in the optimum form for coagulating function is always a key problem for preparing high level flocculants and commercial products. Typically, the study of hydrolysis of $\mathrm{Fe}(\mathrm{III})$ is carried out on partially neutralized solution prepared by slow addition of base. The extent of hydrolysis and polymerization is characterized with the operation parameter $B$ $(=\mathrm{OH} / \mathrm{Fe})$ and more precisely by hydrolysity $B^{*}$ (Tang and Stumm, 1987; Tang, 1990). Four regions can be distinguished from a typical titration curve, which can be roughly related to the types of polymeric ferric solutions by combining with the comprehensive chemical model of Tang and Stumm (1987). Obviously, to preform stable Fe(III) polymers, it needs to cross the first precipitation zone (roughly $0.2<B^{*}<0.5$ ) and prevent homogeneous amorphous precipitation $\left(B^{*}>1.5\right)$. Despite numerous investigations, the mechanism of hydrolysispolymerization-precipitation of $\mathrm{Fe}(\mathrm{III})$ and the quantitative principles are still not perfectly clear (Van De Woude and De Bruyn, 1983; Melikov, 1987; Khoe and Robins, 1989). The nature and behavior of hydrolysis products are controlled by many factors, such as the components and concentration of the primary $\mathrm{Fe}(\mathrm{III})$ solution, $\mathrm{pH}$, components of coexisting anions, temperature, time of aging, traces of contaminants including dust particles, which can seed the precipitation of the solid, preparation methods and other topchemical transformation. Generally speaking, with physical conditions established, the salient deciding factor is anion components.

In view of this, to prevent iron species from precipitating, the following three kinds of materials might act as modifiers: (1) inorganic anions such as sulfates, phosphates, or silicates; (2) organic anions such as various organic acids, surfactants; and (3) artificial or natural organic polyelectrolytes such as polyalcohol, polyose. The mechanism of their hydrolysis-precipitation inhibition might be attributed to their coordinate effects with iron monomers to influence the subsequent polymerization process as result, or direct combination with iron polymers to prevent further polymerization. Anyway, the modifiers chosen to prepare flocculant should satisfy the following conditions: (1) no deterioration on the efficiency of $\mathrm{PFCl}$ as flocculant; (2) without toxicity, and other after effects during water treatment;
(3) convenient to be applied and with low cost. According to these, inorganic anions may be of first choice. Besides phosphate, the silica species are in preference for their strong coordinate and aggregating effects and they also possess a few particular different aqueous behaviors (Iler, 1979).

In aqueous solutions, a variety of polymeric silica species can be formed. By the silica-molybdate acid analysis method (Iler, 1979), they can be classified into three categories as $\mathrm{Si}_{\mathrm{a}}$ (monomers), $\mathrm{Si}_{\mathrm{b}}$ (oligomers) and $\mathrm{Si}_{\mathrm{c}}$ (polymers and colloids) like the ferron method (Hsu and Cao, 1990) performed with hydrolyzed $\mathrm{Al}(\mathrm{III})$ and $\mathrm{Fe}(\mathrm{III})$ species. Since the separation and purification of these species are very difficult, three kinds of silica, named silicaA, silicaB and silicaC, are first prepared containing different amounts of the above silica species. The significance of various silica on hydrolysis and polymerization of $\mathrm{Fe}(\mathrm{III})$ and their subsequent effect on coagulation become the focus of this study.

\section{MATERIALS AND METHODS}

\section{Preparation of modifiers}

All reagents used were of analytical reagent grade except those being pointed out. Before the preparation of PFSi, three kinds of modifiers, silicaA, silicaB and silicaC, were first prepared. SilicaA and silicaB were prepared by acidification of reagent $\mathrm{Na}_{2} \mathrm{SiO}_{3}$ and industrial water glass solutions, respectively, using $\mathrm{HCl}$. SilicaA was prepared first as $0.6 \mathrm{~mol} / \mathrm{L}$ stock solution of $\mathrm{Na}_{2} \mathrm{SiO}_{3}$. Before use, a certain amount of stock solution was titrated into diluted $\mathrm{HCl}$ solution at a rate of $0.5 \mathrm{ml} / \mathrm{s}$ under rapid stirring using 665Dosimat Titraprocessor (Metrohm, Sweden). The final $\mathrm{pH}$ was 1.80 , and the concentration of $\mathrm{Si}$ was $0.40 \mathrm{~mol} / \mathrm{L}$. SilicaB was prepared using the same procedure, except that $0.6 \mathrm{~mol} / \mathrm{L}$ (Si) diluted water glass solution was prepared insitu and used immediately. SilicaC was traditional activated silica, prepared from industrial water glass by neutralizing $83 \%$ of its alkalinity and aged for $1 \mathrm{~h}$. The main characteristic and results of speciation as characterized using $\mathrm{Si}-\mathrm{Mo}$ assay are summarized in Table 1.

In summary, silicaA contains mainly monomer and low polymer with $\mathrm{Si}_{\mathrm{a}} 71.4 \%, \mathrm{Si}_{\mathrm{b}} 13.3 \%$ and $\mathrm{Si}_{\mathrm{c}} 15.3 \%$. The species distribution in silicaB is $\mathrm{Si}_{\mathrm{a}} 26.6 \%, \mathrm{Si}_{\mathrm{b}} 9.40$ and $\mathrm{Si}_{\mathrm{c}}$ $64.0 \%$, and silicaC contains mainly $\mathrm{Si}_{\mathrm{c}},>96 \%$. It must be pointed out that the $\mathrm{Si}_{\mathrm{c}}$ component in the above silica differentiates significantly. The reaction rate constant, $k_{\mathrm{c}}$, was $0.0244,0.0094$ and 0.0002 for silicaA, silicaB and silicaC respectively. Only in silicaC, the $\mathrm{Si}_{\mathrm{c}}$ component can be detected by photon correlation spectroscopy (PCS).

Table 1. Species distribution of three kinds of silica

\begin{tabular}{lccccc}
\hline Silica & $\mathrm{Si}_{\mathrm{a}}(\%)$ & $\mathrm{Si}_{\mathrm{b}}(\%)$ & $\mathrm{Si}_{\mathrm{c}}(\%)$ & $k_{\mathrm{c}}$ & $d(\mathrm{~nm})^{\mathrm{a}}$ \\
\hline Stand. Si & 100 & 0 & 0 & 0.294 & $\mathrm{UD}^{\mathrm{b}}$ \\
Silica $(A)$ & 72.1 & 13.8 & 14.1 & 0.0279 & $\mathrm{UD}$ \\
Silica $(B)$ & 26.6 & 9.4 & 64.0 & 0.0095 & $\mathrm{UD}$ \\
Silica $(C)$ & 1.4 & 0.0 & 98.6 & 0.0001 & 47.3 \\
\hline
\end{tabular}

${ }^{\mathrm{a}}$ Measured by PCS using Cumulants analysis.

${ }^{\mathrm{b}}$ Undetectable by PCS. 
Preparation of $\operatorname{PFSi}(A, B, C)$

Three kinds of PFSi $(\mathrm{A}-\mathrm{C})$ were prepared from silica (A-C) respectively. A stock solution was prepared as $3.1 \mathrm{~mol} / \mathrm{L} \mathrm{FeCl}_{3}$. The prepared silica solution was quickly added into a certain amount of diluted $\mathrm{FeCl}_{3}$ stock solution under vigorous stirring at the predetermined $\mathrm{Si} / \mathrm{Fe}$ ratio, i.e. 2.0, 1.0, 0.5 and 0.2. Under rapid stirring at room temperature, $0.5 \mathrm{~mol} / \mathrm{L} \mathrm{NaHCO}_{3}$ was titrated micro-dropwise at a flow rate of $0.6 \mathrm{ml} / \mathrm{min}$ into above solution. The volume of $\mathrm{NaHCO}_{3}$ was varied depending on the desired basicity $\mathrm{B}$ at $0,0.6,1.0$ (corresponding to type $\mathrm{A}$ and $\mathrm{C}$ of $\mathrm{PFCl}$, Tang and Stumm, 1987), respectively. The final $\mathrm{Fe}(\mathrm{III})$ concentration was $0.3 \mathrm{~mol} / \mathrm{L}$. The serial numbers of samples are explained in Table 2. The $\mathrm{pH}$ evolution was recorded immediately after sample preparation was finished.

\section{Characterization methods}

Two main kinds of speciation methods, i.e., the timed complexation spectroscopy method and PCS analysis, were applied. The timed complexation spectroscopy methods were ferron methods to differentiate $\mathrm{Fe}(\mathrm{III})$ species, and $\mathrm{Si}-\mathrm{Mo}$ methods to differentiate silica species, respectively. The experiments were run on Beckman DU650-UV-Visible Spectrometer. The PCS measurements were performed on a Brookhaven Model BI-200SM servomotor-controlled light scattering gonimeter with a Model BI-9000AT autocorrelator (Wang et al., 2000). The incident light source was a $35 \mathrm{~mW} \mathrm{He}-\mathrm{Ne}$ laser operating at a $632.8-\mathrm{nm}$ wavelength with vertical polarization. The instrument alignment was checked by the BI-IST software, the deviations were less than $2 \%$ over the angular range.

\section{Coagulation experiments}

A stock suspension of clay particles was first prepared by dispersing powder kaolin in deionized water to a concentration of $50 \mathrm{~g} / \mathrm{L}$ and preserved in refrigerator. The stock suspension was finely mixed prior to use. Then under rapid stirring a certain quantity was transferred to test water, which contained $5 \times 10^{-4} \mathrm{~mol} / \mathrm{L} \mathrm{NaHCO}_{3}$ and $\mathrm{NaNO}_{3}$, respectively. Therefore, the effect of bicarbonate ion was controlled at a constant range (Letterman et al., 1979). A total amount of $20 \mathrm{~L}$ suspension was prepared for batch experiments. The size distribution of the kaolin suspension was measured by a particle counter (Multisizer II, Coulter Electronics, Hialeah, FL, USA). The results showed that the particles in the suspension had a mean volume diameter of $2.28 \mu \mathrm{m}$ with a relatively narrow size distribution. The specific surface area of kaolin was $30.2 \mathrm{~m}^{2} / \mathrm{g}$ measured by an accelerated surface and porosity system (2000AP, Micrometrics, USA). Electrophoretic mobility (EM) of the kaolin particles was measured by a laser zeta potential analyzer (Zetaplus, BIC, NY, USA). It was found that the particles were negatively charged at all $\mathrm{pH}$ values measured (from 3.0 to 11.0 ).

For the purpose of evaluating the coagulation efficiency, the conventional jar test was applied using a standard bench-stirrer (PB-700 JarTester, Phipps \& Bird, Richmond, VA, USA). The jar test was carried out in beakers of $600 \mathrm{ml}$. The target $\mathrm{pH}$ was adjusted by adding predetermined amounts of 0.1 and $0.02 \mathrm{~mol} / \mathrm{L} \mathrm{HCl}$ or $\mathrm{NaOH}$ to the suspension. Coagulation experiments with a $0.3 \mathrm{~mol} / \mathrm{L}$ ferric chloride solution, which has been classified as type A based on the analysis of Tang and Stumm (1987) was also conducted for comparisons. During the rapid mixing the coagulants were dosed by a milli-injector. The initial rapid mixing with $200 \mathrm{rpm}$ was used to obtain swift homogeneous dispersion. The rapid mixing of $30 \mathrm{~s}$ was followed by slow mixing for $15 \mathrm{~min}$ at speed of $40 \mathrm{rpm}$. Then the suspension was left to settle for $10 \mathrm{~min}$. After settling, the sample was collected at $2.0 \mathrm{~cm}$ beneath the surface for residual turbidity (RT) measurement using a model turbidimeter (NDH-20, Japan). EM was measured just after the rapid mixing using the BIC-Zetaplus.

\section{RESULTS AND DISCUSSION}

\section{pH evolution and stability}

The $\mathrm{pH}$ values were monitored immediately after sample preparation. It is found that the silica $(A, B, C)$ modified ferric chloride (PFSi at $B=0$ ), all maintain steadily the same $\mathrm{pH}$ value. With PFSi samples at $B=0.6$, the $\mathrm{pH}$ value decreases with aging but at a different range for the different kinds of silica and $\mathrm{Si} /$ Fe ratio applied (Fig. 1). Silica $(A)$ and silica $(B)$ show similar pattern of decreasing the $\mathrm{pH}$ with increasing of $\mathrm{Si} / \mathrm{Fe}$ ratio. However, silica $(C)$ shows little effect of $\mathrm{Si} / \mathrm{Fe}$ ratio on $\mathrm{pH}$. The $\mathrm{PFSi}$ samples at $B=1.0$ appear to have the same trend as $B=0.6$.

The stability of the samples was observed under the same room temperature, and the results are shown in Table 3. With silica modification at moderate $\mathrm{Si} / \mathrm{Fe}$ ratio $(0.2-1)$, the stability of solution is markedly improved. Some of the samples stand above 1 year without precipitation. However, with $\mathrm{Si} / \mathrm{Fe}$ ratio increases more than 1 , the stability of sample deteriorates again. Some of the samples finally become gel.

In order to understand further the effect of different kinds of silica on the hydrolysis of $\mathrm{Fe}(\mathrm{III})$, the first precipitation zone for different silica at $\mathrm{Si} / \mathrm{Fe}$

Table 2. The serial numbers of samples

\begin{tabular}{|c|c|c|c|c|c|c|}
\hline \multirow[t]{2}{*}{ B } & \multirow[t]{2}{*}{ Silica } & \multicolumn{5}{|c|}{$\mathrm{Si} / \mathrm{Fe}$ ratio } \\
\hline & & 2.0 & 1.0 & 0.5 & 0.2 & 0 \\
\hline \multirow{3}{*}{0} & $A$ & OPFSi $A 20$ & $0 P F S i A 10$ & OPFSi $A 05$ & OPFSi $A 02$ & \\
\hline & $B$ & OPFSi $B 20$ & $0 \mathrm{PFSi} B 10$ & OPFSi $B 05$ & $0 \mathrm{PFSi} B 02$ & OPFC \\
\hline & $\mathrm{C}$ & OPFSiC20 & $0 \mathrm{PFSi} C 10$ & 0PFSiC05 & OPFSiC02 & $\left(\mathrm{FeCl}_{3}\right)$ \\
\hline \multirow{3}{*}{0.6} & $A$ & 06PFSi $A 20$ & $06 \mathrm{PFSi} A 10$ & 06PFSi $A 05$ & 06PFSi $A 02$ & \\
\hline & $B$ & 06PFSi $B 02$ & 06PFSi $B 10$ & 06PFSiB05 & 06PFSi $B 02$ & $06 \mathrm{PFC}$ \\
\hline & $C$ & 06PFSiC02 & 06PFSiC10 & 06PFSiC05 & 06PFSiC02 & \\
\hline \multirow{3}{*}{1.0} & $A$ & 10PFSi $A 20$ & 10PFSi $A 10$ & 10PFSi $A 05$ & 10PFSi $A 02$ & \\
\hline & $B$ & 10PFSi $B 20$ & 10PFSi $B 10$ & 10PFSi $B 05$ & 10PFSi $B 02$ & 10PFC \\
\hline & $C$ & 10PFSiC20 & 10PFSiC 10 & 10PFSiC05 & 10PFSiC02 & \\
\hline
\end{tabular}


ratio of 1 was investigated as shown in Fig. 2. It is interesting to note that the precipitation region is significantly narrowed with modification of silica $(A)$ and silica $(B)$, while silica $(C)$ exhibits only limited effect.
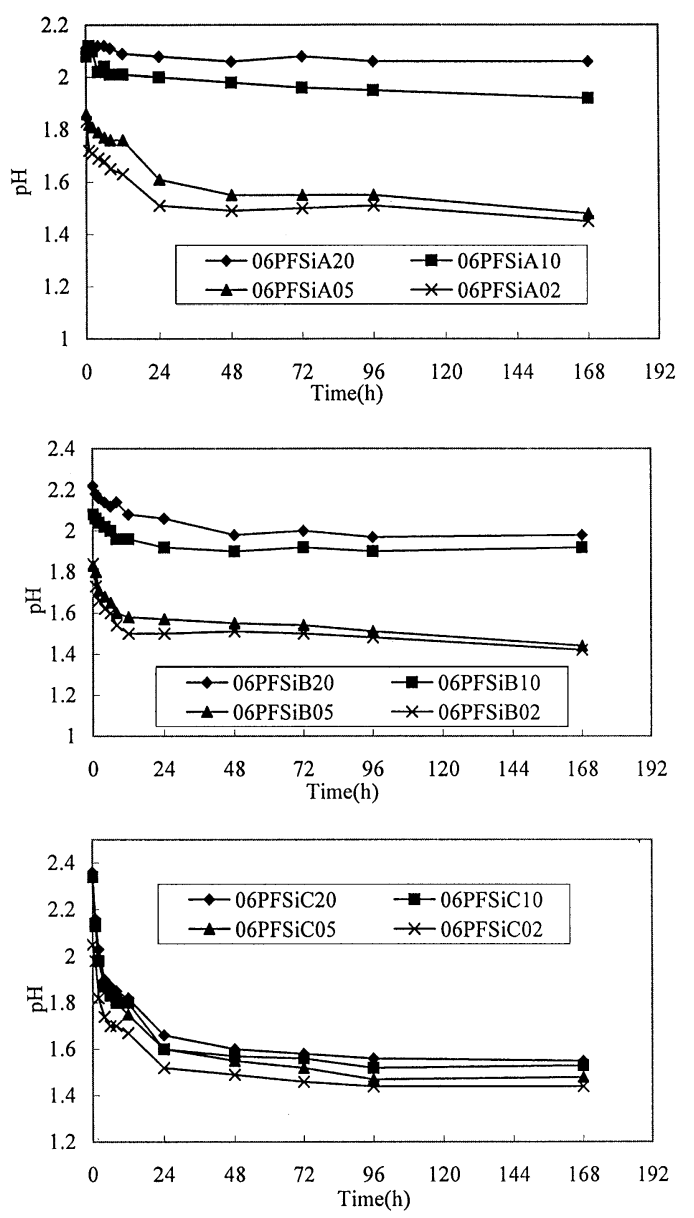

Fig. 1. The $\mathrm{pH}$ evolution of PFSi at $B=0.6$.

\section{Speciation by ferron assay}

The speciation of all samples was run after $24 \mathrm{~h}$ aging. Results obtained from ferron assay are summarized at Table 4. Along with the increase of $B$, the amount of $\mathrm{Fe}_{\mathrm{a}}$ decreases, while the amount of $\mathrm{Fe}_{\mathrm{c}}$ increases markedly. However, the $\mathrm{Fe}_{\mathrm{b}}$ species are still the minor components, existing only between $2 \%$ and $10 \%$. The maximum is not more than $15 \%$. It increases only slightly with increase of $B$. Compared with the results of PFCl (Gray et al., 1995; Tian and Tang, 1989), the same trend of species distribution is observed. The increase of basicity promotes mainly the amount of $\mathrm{Fe}_{\mathrm{c}}$ with little yield of $\mathrm{Fe}_{\mathrm{b}}$.

Table 4 illustrates simultaneously the effect of types of silica and $\mathrm{Si} / \mathrm{Fe}$ ratio. At $B=0$, the only species existing are $\mathrm{Fe}_{\mathrm{a}}$. Silica exhibits no effect. With the increase of $B$ to 0.6 and 1.0, the effect of silica becomes obvious. Silica $(A)$ shows a similar effect as silica $(B)$. By increasing the $\mathrm{Si} / \mathrm{Fe}$ ratio, $\mathrm{Fe}_{\mathrm{a}}$ and $\mathrm{Fe}_{\mathrm{b}}$ increase, however, $\mathrm{Fe}_{\mathrm{c}}$ decreases significantly. Thus, at certain amount of $\operatorname{silica}(A)$ and silica $(B)$, the further hydrolysis of $\mathrm{Fe}(\mathrm{III})$ can be inhibited. But with silica $(C)$, to the contrary, the increases of $\mathrm{Si} / \mathrm{Fe}$ ratio has little effect on the species distribution, which is almost similar as the sample of PFCl. Hence, the kinds of silica introduced have significant effect on the species distribution of PFSi corresponding with $\mathrm{Si} / \mathrm{Fe}$ ratio. Silica $(A)$ and $\operatorname{Silica}(B)$ are more active than silica $(C)$ in preventing the hydrolysis of $\mathrm{Fe}(\mathrm{III})$, through strong complexation or stereo combination with $\mathrm{Fe}(\mathrm{III})$ species by interaction of type $-\mathrm{Fe}\left(\mathrm{OH}_{2}\right)^{+}+-\mathrm{SiO}(\mathrm{OH})_{3}^{-} \Leftrightarrow-\mathrm{FeOSi}(\mathrm{OH})_{3}+\mathrm{H}_{2} \mathrm{O}$. However, silica $(C)$ appears inert to the hydrolysis of $\mathrm{Fe}(\mathrm{III})$ and this may contribute to its bigger particle size and with little amount of surface active $\mathrm{SiOH}$ group available in comparison with silica $(A)$ and silica $(B)$. By increasing the $\mathrm{Si} / \mathrm{Fe}$ ratio, more quantity of $\mathrm{Fe}(\mathrm{III})$ is complexed as indicated from the increase of $\mathrm{Fe}_{\mathrm{a}}$ and this may interfere with subsequent polymerization and particle growth. As shown previously in Fig. 2, the first precipitation zone is

Table 3. The stability of samples

\begin{tabular}{|c|c|c|c|c|c|c|c|c|}
\hline No. & $\mathrm{Si} / \mathrm{Fe}$ & Stability & No. & $\mathrm{Si} / \mathrm{Fe}$ & Stability & No. & $\mathrm{Si} / \mathrm{Fe}$ & Stability \\
\hline $0 P F S i A 20$ & 2.0 & Gel & $06 \mathrm{PFSi} A 20$ & 2.0 & $70^{\mathrm{a}}$ & $10 \mathrm{PFSi} A 20$ & 2.0 & 85 \\
\hline $0 \mathrm{PFSi} A 10$ & 1.0 & b & $06 \mathrm{PFSi} A 10$ & 1.0 & 1 & $10 \mathrm{PFSi} A 10$ & 1.0 & 1 \\
\hline OPFSi $A 05$ & 0.5 & 1 & 06PFSi $A 05$ & 0.5 & 152 & 10PFSi $A 05$ & 0.5 & 167 \\
\hline OPFSi $A 02$ & 0.2 & / & 06PFSi $A 02$ & 0.2 & 141 & 10PFSi $A 02$ & 0.2 & 138 \\
\hline OPFSi $B 20$ & 2.0 & Gel & 06PFSi $B 20$ & 2.0 & 118 & 10PFSi $B 20$ & 2.0 & / \\
\hline $0 P F S i B 10$ & 1.0 & / & $06 \mathrm{PFSi} B 10$ & 1.0 & / & $10 \mathrm{PFSi} B 10$ & 1.0 & i \\
\hline $0 P F S i B 05$ & 0.5 & / & 06PFSi $B 05$ & 0.5 & / & 10PFSi $B 05$ & 0.5 & / \\
\hline $0 \mathrm{PFSi} B 02$ & 0.2 & / & 06PFSi $B 02$ & 0.2 & 149 & 10PFSi $B 02$ & 0.2 & 152 \\
\hline 0PFSiC20 & 2.0 & 64 & 06PFSiC20 & 2.0 & 84 & 10PFSiC20 & 2.0 & / \\
\hline 0PFSiC 10 & 1.0 & 102 & 06PFSiC 10 & 1.0 & l & 10PFSiC10 & 1.0 & / \\
\hline OPFSiC05 & 0.5 & 1 & 06PFSiC05 & 0.5 & i & 10PFSiC05 & 0.5 & 1 \\
\hline OPFSiC02 & 0.2 & / & 06PFSiC02 & 0.2 & 87 & 10PFSiC02 & 0.2 & 94 \\
\hline OPFC & 0 & / & $06 \mathrm{PFC}$ & 0 & 55 & 10PFC & 0 & 70 \\
\hline
\end{tabular}

${ }^{\text {a }}$ Destabilized time (day).

${ }^{\mathrm{b}}$ No precipitation observed. 
markedly modified in presence of silica $(A)$ and silica $(A)$. However, the species distribution and transformation mode has not been changed. The main species generated are $\mathrm{Fe}_{\mathrm{a}}$ and $\mathrm{Fe}_{\mathrm{c}}$, no significant increase of $\mathrm{Fe}_{\mathrm{b}}$ is observed. It is found that the subunits of iron hydroxide sols influenced by the type of anions present are in the size range of $16 \AA$ in chloride solution (a model of polymer containing 24 $\mathrm{Fe}$ atoms is also proposed) or vary from 7 up to $13.5 \AA$ in nitrate solution (Bottero et al., 1991; Tchoubar et al., 1991). It seems thus that these polymers once formed lack enough stability and quickly undergo aggregation or coalescence. The function of silica is mostly on retarding the formation of these subunits and also $\mathrm{Fe}_{\mathrm{c}}$ as result. The stabilization of these subunits could still not be achieved in chloride and nitrate solutions. It is noteworthy that with the presence of silica, the species of $\mathrm{Fe}_{\mathrm{a}}, \mathrm{Fe}_{\mathrm{b}}$ and $\mathrm{Fe}_{\mathrm{c}}$ in PFSi samples are no longer the same as that in single $\mathrm{PFCl}$ solutions. They are all in a state of complexation or combination with silica species.

\section{Speciation by molybdic acid assay}

Due to the analytical limitation, only suitable samples aged for $24 \mathrm{~h}$ were analyzed using Molybdic

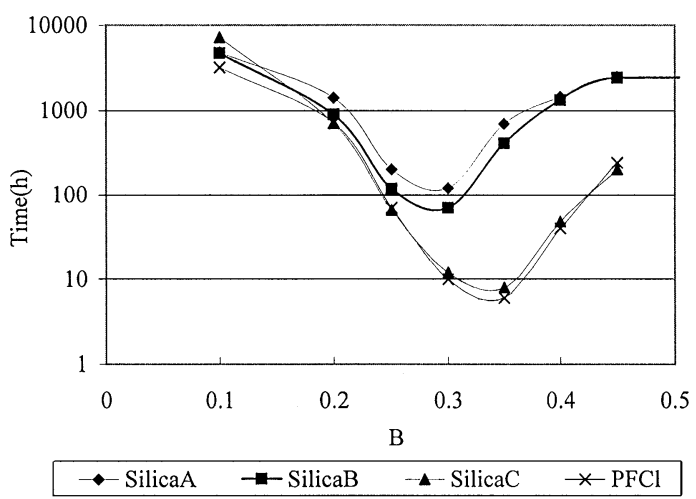

Fig. 2. Effect of silica on the first precipitation zone of Fe(III). acid method, and PCS determination is described as follows. The results of PFSiA and PFSiB are summarized in Table 5. For comparison, the results of aged silica $(A)$ and silica $(B)$ are also displayed.

It can be seen also that $B$ value has important effect on the existing state of silica species in PFSi. At $B=0$, the characteristic of species distribution of samples remains similar mode of silica introduced, while the species of original silica sample change quickly after $24 \mathrm{~h}$ aging. Obviously, complexation with $\mathrm{Fe}(\mathrm{III})$ inhibits further polymerization of silica. However, as $B$ increases, the species distribution of silica in PFSiA changes markedly, and differentiates with $\mathrm{Si} / \mathrm{Fe}$ ratio. By increasing $\mathrm{Si} /$ $\mathrm{Fe}$ ratio, the amount of $\mathrm{Si}_{\mathrm{b}}$ and $\mathrm{Si}_{\mathrm{c}}$ increase, indicating the combination between silica and hydrolyzed $\mathrm{Fe}(\mathrm{III})$ species is reinforced with alkalinity addition.

\section{Speciation by PCS}

The lowest limit of detection for the PCS instrument is the particle size of about $1-5 \mathrm{~nm}$. However, only those with scattering intensity above $1 \mathrm{kcps}$ were reliable. All the samples of $0 \mathrm{PFSi} A, 0 \mathrm{PFSi} B$, 06PFSi $A 20,06 \mathrm{PFSi} A 10,06 \mathrm{PFSi} B 20$ and $10 \mathrm{PFSi} A 20$ do not have enough scattering intensity. As shown from Tables 4 and 5, the mainly existing species in above samples are $\mathrm{Fe}_{\mathrm{a}}$ and $\mathrm{Si}_{\mathrm{a}}$. Therefore the PCS diagram represents mainly the particle size distribution of $\mathrm{Fe}_{\mathrm{c}}$ and $\mathrm{Si}_{\mathrm{c}}$. Figure 3 shows some of the results of PCS measurements of $\mathrm{PFSi} B$ at $B=1.0$.

The PCS diagrams show that along with the increase of $\mathrm{Si} / \mathrm{Fe}$ ratio, more complicated polymers are formed and the particle size distribution is of range and multidispersed. It is evident that some of copolymerized species or aggregates between silica and iron(III) polymers are formed. By decreasing the $\mathrm{Si} / \mathrm{Fe}$ ratio, the particle distribution becomes typically that of $\mathrm{PFCl}$ (Bottero et al., 1991; Wang et al., 2000), i.e., exhibiting a narrow distribution with particle diameter at several $\mathrm{nm}$.

Table 4. The speciation of $\operatorname{PFSi}(A, B, C)$ : ferron assay

\begin{tabular}{|c|c|c|c|c|c|c|c|c|c|c|c|}
\hline No. & $\mathrm{Fe}_{\mathrm{a}}(\%)$ & $\mathrm{Fe}_{\mathrm{b}}(\%)$ & $\mathrm{Fe}_{\mathrm{c}}(\%)$ & No. & $\mathrm{Fe}_{\mathrm{a}}(\%)$ & $\mathrm{Fe}_{\mathrm{b}}(\%)$ & $\mathrm{Fe}_{\mathrm{c}}(\%)$ & No. & $\mathrm{Fe}_{\mathrm{a}}(\%)$ & $\mathrm{Fe}_{\mathrm{b}}(\%)$ & $\mathrm{Fe}_{\mathrm{c}}(\%)$ \\
\hline $0 P F S i A 20$ & 100 & 0 & 0 & 06PFSi $A 20$ & 97.8 & 2.2 & 0.0 & $10 \mathrm{PFSi} A 20$ & 85.0 & 11.6 & 3.4 \\
\hline $0 P F S i A 10$ & 100 & 0 & 0 & 06PFSi $A 10$ & 95.7 & 4.3 & 0.0 & 10PFSi $A 10$ & 77.7 & 15.9 & 6.4 \\
\hline $0 P F S i A 05$ & 100 & 0 & 0 & $06 \mathrm{PFSi} A 05$ & 89.3 & 4.0 & 6.7 & $10 \mathrm{PFSi} A 05$ & 72.2 & 7.6 & 20.2 \\
\hline OPFSi $A 02$ & 100 & 0 & 0 & 06PFSi $A 02$ & 81.0 & 3.1 & 15.9 & $10 \mathrm{PFSi} A 02$ & 64.5 & 4.9 & 30.6 \\
\hline 0 PFSi $B 20$ & 100 & 0 & 0 & $06 \mathrm{PFSi} B 20$ & 98.1 & 1.9 & 0.0 & 10 PFSi $B 20$ & 87.8 & 6.7 & 5.5 \\
\hline $0 P F S i B 10$ & 100 & 0 & 0 & $06 \mathrm{PFSi} B 10$ & 96.7 & 3.3 & 0.0 & $10 \mathrm{PFSi} B 10$ & 77.1 & 7.6 & 15.3 \\
\hline $0 P F S i B 05$ & 100 & 0 & 0 & $06 \mathrm{PFSi} B 05$ & 83.8 & 2.7 & 13.5 & $10 \mathrm{PFSi} B 05$ & 71.9 & 5.5 & 22.6 \\
\hline 0 PFSi $B 02$ & 100 & 0 & 0 & $06 \mathrm{PFSi} B 02$ & 81.3 & 2.4 & 16.3 & $10 \mathrm{PFSi} B 02$ & 67.9 & 5.5 & 26.6 \\
\hline OPFSiC20 & 100 & 0 & 0 & 06PFSiC20 & 78.2 & 1.3 & 20.5 & 10PFSiC20 & 58.4 & 8.9 & 32.7 \\
\hline OPFSiC 10 & 100 & 0 & 0 & $06 \mathrm{PFSi} C 10$ & 77.4 & 2.5 & 20.1 & 10PFSiC 10 & 60.2 & 8.0 & 31.8 \\
\hline OPFSiC05 & 100 & 0 & 0 & 06PFSiC05 & 79.7 & 1.9 & 18.4 & 10PFSiC05 & 62.4 & 7.0 & 30.6 \\
\hline OPFSiC02 & 100 & 0 & 0 & 06PFSiC02 & 77.4 & 2.4 & 20.2 & 10PFSiC02 & 63.4 & 4.0 & 32.6 \\
\hline OPFC & 100 & 0 & 0 & $06 \mathrm{PFC}$ & 79.4 & 2.5 & 18.1 & $10 \mathrm{PFC}$ & 64.7 & 2.8 & 32.5 \\
\hline
\end{tabular}




\section{Coagulation efficiency}

The coagulation results and change of particle charge with dosage of PFSi at $B=0$ are shown in Fig. 4. Although the samples are all prepared at basicity of 0 , the capability of charge neutralization is distinguished from each other and differentiates markedly with the kinds of silica used and the

Table 5. The speciation of PFSi by Si-Mo assay

\begin{tabular}{lrrr}
\hline No. & $\mathrm{Si}_{\mathrm{a}}(\%)$ & $\mathrm{Si}_{\mathrm{b}}(\%)$ & $\mathrm{Si}_{\mathrm{c}}(\%)$ \\
\hline Silica $A$ 0 h & 72.1 & 13.8 & 14.1 \\
Silica $A$ 24 h & 14.3 & 1.8 & 83.9 \\
0PFSi $A 20$ & 74.4 & 10.2 & 15.4 \\
0PFSi $A 10$ & 72.4 & 14.3 & 13.3 \\
0PFSi $A 05$ & 71.8 & 13.8 & 14.4 \\
OPFSi $A 02$ & 71.8 & 12.6 & 15.6 \\
06PFSi $A 20$ & 25.2 & 9.9 & 64.9 \\
06PFSi $A 10$ & 30.1 & 15.7 & 54.2 \\
06PFSi $A 05$ & 39.4 & 10.3 & 50.3 \\
06PFSi $A 02$ & 72.8 & 11.2 & 16.0 \\
10PFSi $A 20$ & 6.7 & 22.8 & 70.5 \\
10PFSi $A 10$ & 14.9 & 31.6 & 55.5 \\
10PFSi $A 05$ & 50.4 & 17.3 & 32.3 \\
10PFSi $A 02$ & 80.9 & 9.2 & 9.9 \\
Silica $B$ 0 h & 26.6 & 9.4 & 64.0 \\
Silica $B$ 24h & 18.2 & 0.4 & 81.4 \\
OPFSi $B 20$ & 24.8 & 7.4 & 67.8 \\
0PFSi $B 10$ & 22.5 & 8.9 & 68.6 \\
0PFSi $B 05$ & 23.2 & 4.1 & 72.7 \\
0PFSi $B 02$ & 30.6 & 2.5 & 66.9 \\
\hline
\end{tabular}

increase of $\mathrm{Si} / \mathrm{Fe}$ ratio. It can be seen from Fig. 4(a) and (b) that for the increase of $\operatorname{PFSi} A$ and $\operatorname{PFSi} B$ dosage, the EM of particles increases and turns into positive gradually. However, the trend decreases quickly with increase of $\mathrm{Si} / \mathrm{Fe}$ ratio, indicating that the charge-neutralization capability of PFSi decreases significantly with the increase of $\mathrm{Si} / \mathrm{Fe}$ ratio. The effect of silica and $\mathrm{Si} / \mathrm{Fe}$ ratio on change of $\mathrm{RT}$ can also be observed clearly from Fig. 4. At low dosage, the higher the $\mathrm{Si} / \mathrm{Fe}$ ratio, the higher residual turbidity, since the particles remain colloidal stable being highly negatively charged. By increasing the dosage, the charge of particles becomes gradually neutralized, thus, particle destabilization takes place. The coagulation efficiency changes then. It is interesting to note that better turbidity removal is observed for $\mathrm{PFSi}$ at moderate $\mathrm{Si} / \mathrm{Fe}$ ratio with particles still negatively charged. Accordingly, during experiment it is observed that the flocs formed are larger and precipitate rapidly.

For PFSiC as shown in Fig. 4(c), the change of EM shows a similar trend of the effect of $\mathrm{Si} / \mathrm{Fe}$ ratio. The higher $\mathrm{Si} / \mathrm{Fe}$ ratio, the lower charge-neutralization capability is exhibited. However, the scale of EM decrease is exhibited only limitedly, while the coagulation behavior is significantly modified with the increase of $\mathrm{Si} / \mathrm{Fe}$ ratio. From the result of $\mathrm{RT}$ curves as shown in Fig. 4(c), it can be seen that turbidity removal is best for samples at high $\mathrm{Si} / \mathrm{Fe}$
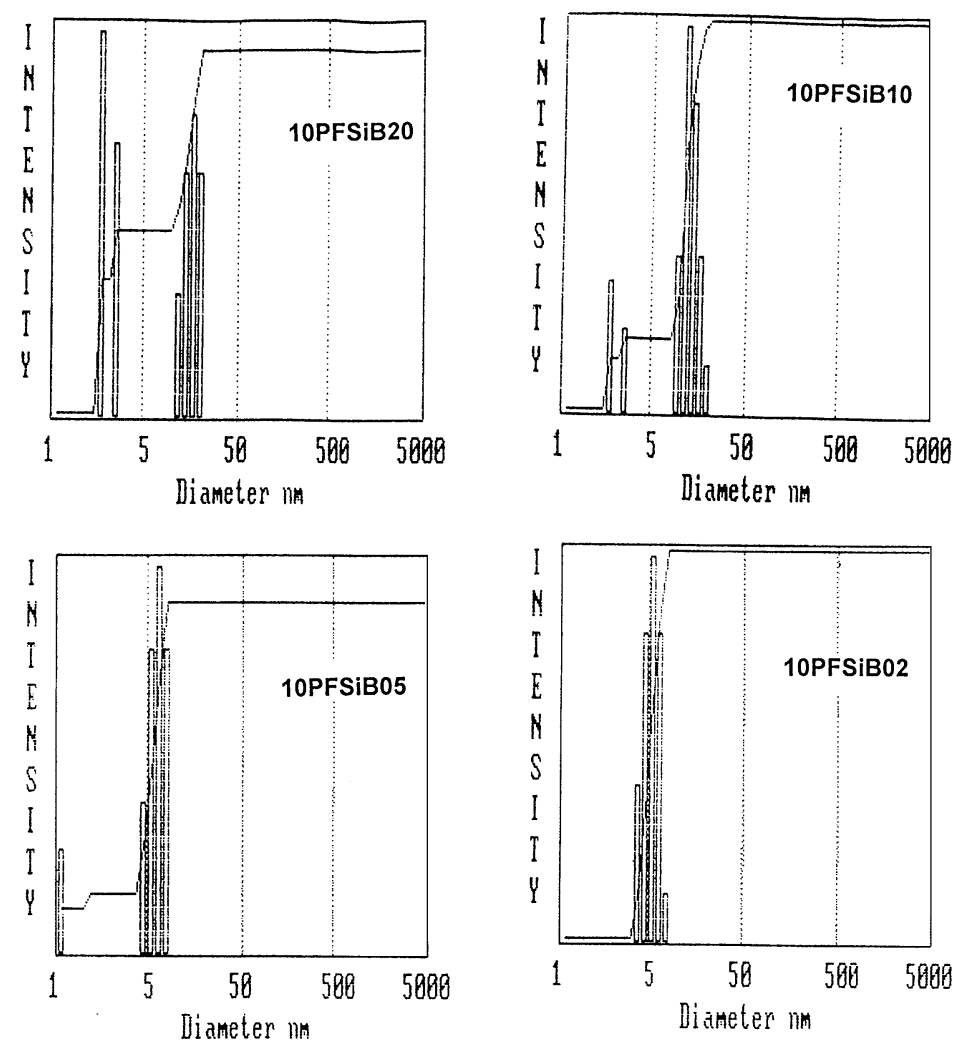

Fig. 3. The typical PCS diagram of PFSi. 

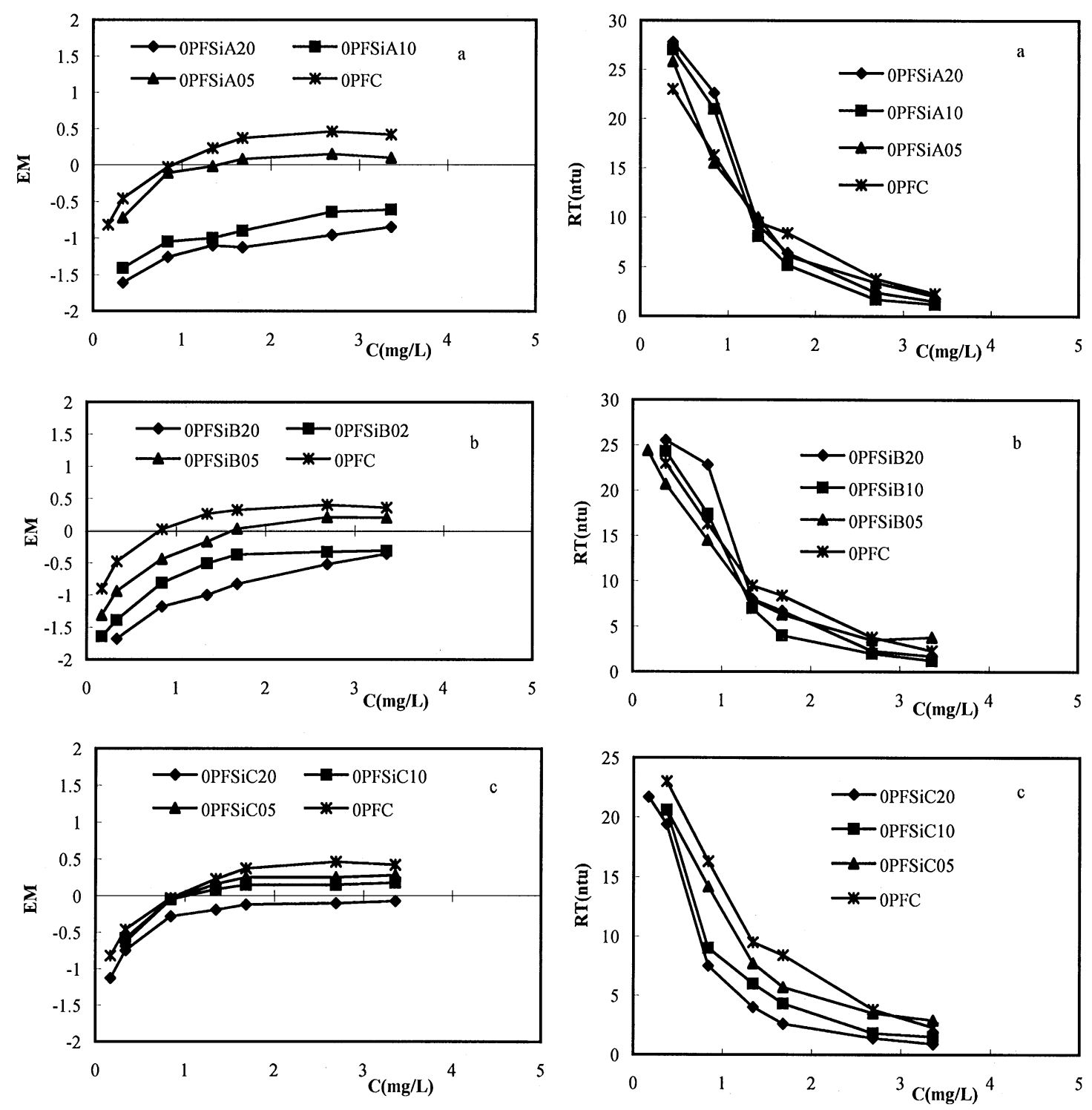

Fig. 4. The coagulation behavior and particle EM change of PFSi at $B=0$.

ratio. The flocs appear again fast, tight and larger, and undergo rapid precipitation.

A similar trend has been found on the other PFSi with higher $B$ values. The typical results of PFSi at $B=1.0$ are shown in Fig. 5. With the increase of coagulant dosage, the EM of particle increases also from negative to positive depending on the kinds of silica and $\mathrm{Si} / \mathrm{Fe}$ ratio. Silica $(A)$ and $\operatorname{silica}(B)$ exhibit a remarkable effect on the charge neutralization ability of PFSi, while silica $(C)$ has only moderate effect.

However, the effect of kinds of silica and $\mathrm{Si} / \mathrm{Fe}$ ratio on the coagulation efficiency becomes more obvious. As shown in Fig. 5, the coagulation of clay particles is greatly inhibited for $\mathrm{PFSi} A$ and $\mathrm{PFSi} B$ at high $\mathrm{Si} / \mathrm{Fe}$ ratio. While at moderate $\mathrm{Si} / \mathrm{Fe}$ ratio, an enhancement of coagulation is observed with the increase of dosage even if particles remain negatively charged. Note that such a modification is still very limited. However, for $\mathrm{PFSiC}$ a remarkable effect of silica $(C)$ is found. Increase of the $\mathrm{Si} / \mathrm{Fe}$ ratio results in efficient coagulation and significant lower residual turbidity.

\section{Mechanism of coagulation with PFSi: Effect of silica}

With the chosen experimental conditions, the difference of coagulation results will mainly be dependent on the composition of coagulants. Based on the ferron assay, the species in PFSi samples can be classified similarly as $\mathrm{Fe}_{\mathrm{a}}, \mathrm{Fe}_{\mathrm{b}}$ and $\mathrm{Fe}_{\mathrm{c}}$, which differs markedly with those in pure $\mathrm{PFCl}$ solutions. The main species, $\mathrm{Fe}_{\mathrm{a}}$ and $\mathrm{Fe}_{\mathrm{b}}$, in the $\mathrm{PFCl}$ solutions at low basicity are highly positive charged monomers and oligomers, such as dimers and trimers (Gray 

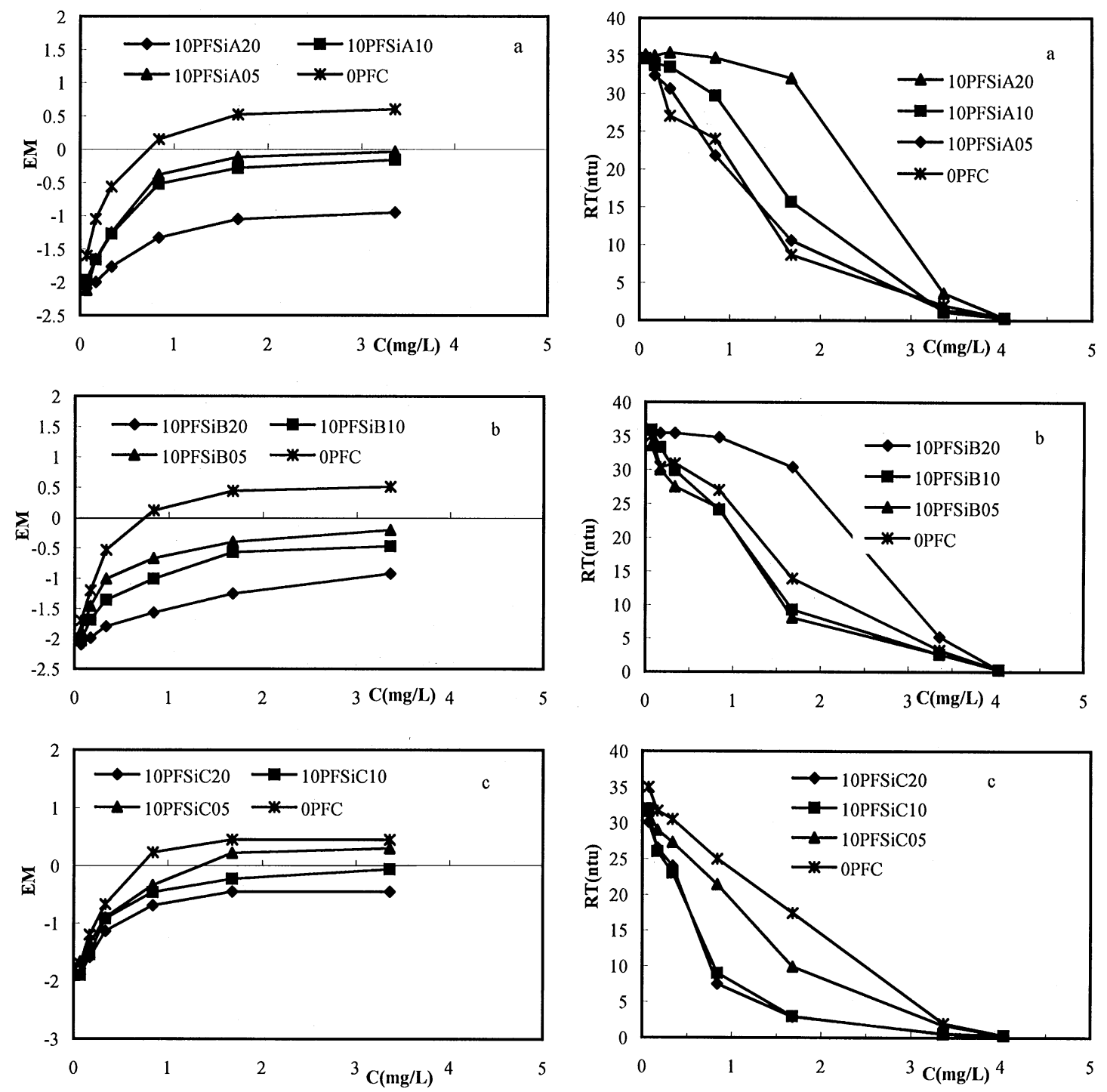

Fig. 5. The coagulation behavior and particle EM change of PFSi at $B=1.0$.

et al., 1995). When added to suspension, they undergo rapid hydrolysis and adsorption, the further hydrolysis species formed are still positively charged and cause efficient charge-neutralization with the negative kaolin particles. In $\operatorname{PFSi} A$ and $\operatorname{PFSi} B$, the main species, $\mathrm{Fe}_{\mathrm{a}}$, are in a state of complexation with silica by interaction of type $-\mathrm{Fe}-\mathrm{OH}_{2}^{+}+\mathrm{Si}(\mathrm{OH})_{4} \Leftrightarrow-$ $\mathrm{Fe}-\mathrm{O}-\mathrm{Si}(\mathrm{OH})_{3}+\mathrm{H}_{3} \mathrm{O}^{+}$. When added to suspension, they also readily undergo hydrolysis and precipitation, since the solution is supersaturated with respect to ferric hydroxide under the experimental conditions. However, the charge of precipitation formed is depended largely on the $\mathrm{Si} / \mathrm{Fe}$ ratio. At high $\mathrm{Si} / \mathrm{Fe}$ ratio, a weaker charged hydrolytic product might be formed with low charge-neutralization capability, resulting in thus deteriorated turbidity removal. By decreasing the $\mathrm{Si} / \mathrm{Fe}$ ratio, the charge of hydrolytic product increases so that charge reversal can then be observed. At higher coagulant dosage, the negatively charged clay particles become gradually neutralized. Particle destabilization is observed. An enhancement of turbidity removal takes place for PFSi at moderate $\mathrm{Si} / \mathrm{Fe}$ ratio even when particles are still negatively charged. Recent study of the effect of soluble silica on the alum coagulation has also shown such a phenomenon (Duan, 1997). Similar improvement of coagulation has been found also with sulfate ion (Letterman, 1983). Although it becomes difficult to interpret the coagulation result with EM, the enhancement is involved closely with the kinetics of precipitation. With the charge effect by the above complexation interaction, the formation of precipitation is kinetically accelerated compared with coagulation of $\mathrm{FeCl}_{3}$. In the meantime, the primary particles formed are in a moderate particle size level (of a few nm as shown in PCS analysis) and their aggregates are fractal objects with rather open structures (Jullien and Bottet, 1987). Therefore, such 
an enhancement takes place only in higher coagulant dosage. A mechanism of electrostatic patch (Gregory, 1973) can also be invoked for such an enhancement. However, in the respects of turbidity removal, it is not economical for high dosage needed.

For $\mathrm{PFSi} C$, the modifier silica $(C)$ is mainly composed of colloid particles, which has little effect on the hydrolysis of Fe(III). The species in PFSiC remain highly positively charged and the effect of charge-neutralization is then maintained. In addition to charge-neutralization coagulation, another mechanism might be taken into effect, where the colloidal silica particles act as the core of hydrolysis products and function as the bridge between clay particles. Therefore, the better turbidity removal is observed at high $\mathrm{Si} / \mathrm{Fe}$ ratios for $\mathrm{PFSiC}$.

At higher basicity, the effect of silica become more evident. As shown previously, by increasing the basicity, $\mathrm{Fe}_{\mathrm{c}}$ is increased with little increase of $\mathrm{Fe}_{\mathrm{b}}$. Therefore, the drop of charge-neutralization capability becomes more significant for $\operatorname{PFSi} A$ and PFSi $B$. It needs to be pointed out that the low basicity chosen here does not affect much the species distribution, and as result a similar coagulation trend is observed.

\section{Indication on the improvement of stable iron-based IPF with high efficiency}

During 1960s and 1970s (Tang and Stumm, 1987; Tang, 1990), PACl, PAS and other sorts of Al-based IPFs were produced and applied on an industrial scale gradually. From the history of development of IPF, it is found that Fe(III), the same trivalent metal ions as $\mathrm{Al}(\mathrm{III})$, is considered first to have a similar behavior of hydrolysis. Therefore, it is assumed that iron salts could be developed similarly into preformed IPF. This point of view became the initial basis for $\mathrm{PFCl}$ preparation. As result, $\mathrm{PFCl}$ with high basicity $(B=2.5)$ similar to that of $\mathrm{PACl}$ was considered to own the best coagulation capability.

However, it is important to pay more attention to the difference rather than the similarity of hydrolysis behavior between $\mathrm{Al}(\mathrm{III})$ and $\mathrm{Fe}(\mathrm{III})$. It is noticed gradually that the hydrolysis trend of Fe(III) is much stronger than that of $\mathrm{Al}(\mathrm{III})$. Under higher $\mathrm{pH}$ situation, the hydrolysis products of $\mathrm{Fe}(\mathrm{III})$ could no longer maintain their charge neutralization ability while aluminum species may be more refractory to hydrolysis and remain markedly positively charged. Furthermore, the primary hydrolysis products, the monomers, differentiate significantly both on their behavior and stereo structure. In a recent report, Martin (1991) considered that the iron monomers remained to be octahedral, while the monomer of $\mathrm{Al}(\mathrm{III})$ underwent a regular reduction from six through five to four-coordinate in the aluminate, $\mathrm{Al}(\mathrm{OH})_{4}^{-}$. The four successive deprotonations from $\mathrm{Fe}^{3+}$ were spaced at about two $\mathrm{pH}$ units while the four $\mathrm{Al}^{3+}$ deprotonations occurred cooperatively and squeeze into an interval of less than one $\mathrm{pH}$ unit. Hence, the Keggin structure as in $\mathrm{Al}_{13}$ polymers can be formed with $\mathrm{Al}$ (III) during alkalinity titration and similar structure for iron is impossible. Even if it might be possible for iron to form the same Keggin structure, the stronger hydrolysis trend would lead to the lower charge of this polymer causing it to become unstable for further polymerization or aggregation. However, the possibility of tetrahedral $\mathrm{Fe}$ has been suspected to be present in ferrihydrites (Cardile, 1989; Combes et al., 1989).

The improvement of coagulation with $\mathrm{PACl}$ may due to the specific characteristic of $\mathrm{Al}_{13}$ both on its union structure and chemical behavior. Recent characterization of acid-base properties of $\mathrm{Al}_{13}$ (Furrer et al., 1992) and coagulation behavior of PACl (Van Benschoten and Edzwald, 1990a,b; Bottero et al., 1981; Parathasarathy and Buffle, 1985; Tang and Luan, 1996) showed that $\mathrm{Al}_{13}$ was quite stable from hydrolysis. It is interesting to note that with tetrahedral $\mathrm{Al}$ present in the center of the structure, the basicity of $\mathrm{Al}_{13}$ maintain is more than 2.0. Thus, it is possible to prepare $\mathrm{PACl}$ at high basicity with large yield of $\mathrm{Al}_{13}$. Under normal slow alkalinity titration, polymer iron species could not exist in a stable state, although many studies revealed that the particles in the stable $\mathrm{Fe}(\mathrm{III})$ sols were consisted of subunits in the range of several $\AA$ (Bottero et al., 1991; Tchoubar et al., 1991). Even with the addition of modifiers such as silica, the readily occurring nucleation-precipitation of $\mathrm{Fe}$ (III) is slowed down due to the complexation effect. However, no higher yield of stable polymers is achieved. From these results, it seems impossible to prepare stable iron(III) polycations in large amount by partially neutralizing with alkalinity titration. However, the improved coagulation efficiency by silica modification indicates other methodology to tailor-make iron-based IPF. With the enhancement by the patch coagulation effect and the general bridge effect, the modified IPF-PFSi exhibits some special merits. Especially for silica $(C)$, a much more efficient and economical turbidity removal could be reached with only slight decrease in charge-neutralization ability. Therefore, a general consideration on the aspects of charge-neutralization capability, precipitation formation, stability and bridge function will be needed for the further development and design of IPFs.

\section{CONCLUSIONS}

Several conclusions can be drawn from the above results:

The property and speciation of modified-PFSi depend significantly on the basicity, the kinds of silica introduced and the $\mathrm{Si} / \mathrm{Fe}$ ratio adopted. Silica $(A)$ and silica $(B)$ function as precipitation preventing reagents during the hydrolysis of $\mathrm{Fe}(\mathrm{III})$. 
At certain amount of basicity, $\mathrm{Fe}_{\mathrm{a}}$ increases with increase of $\mathrm{Si} / \mathrm{Fe}$ ratio, while $\mathrm{Fe}_{\mathrm{c}}$ decreases markedly. Although the formation of $\mathrm{Fe}_{\mathrm{c}}$ is inhibited, the stabilization of $\mathrm{Fe}_{\mathrm{b}}$ can still not be achieved. Silica $(C)$ on the other hand exhibits little effect on the species distribution of modified Fe(III) solutions. However, the trend of species distribution observed is similar as that of $\mathrm{PFCl}$. It seems that iron polymers once formed lack enough stability and undergo quickly aggregation or coalescence. The function of silica is mostly on retarding the formation of these subunits and also $\mathrm{Fe}_{\mathrm{c}}$ as result.

The coagulation efficiency of $\mathrm{PFCl}$ is markedly modified with introduction of silica. The chargeneutralization ability is deteriorated for $\operatorname{silica}(A)$ and silica $(B)$ modified PFSi. At certain dosage, an enhancement of coagulation can be achieved through a mechanism of electrostatic patch effect. With the introduction of silica $(C)$, slight decrease on chargeneutralization is observed, while significant enhancement of coagulation is obtained. However, it seems impossible to prepare stable iron(III) polycations in large amount by partially neutralizing with alkalinity as that of PACl. Preparation of IPF with higher efficiency may be approached by increasing the bridge effect. It should also be pointed out that due to the complicated nature of quality from water to water, a scientific design and application is needed based on the primary water quality conditions.

Acknowledgements - The help and discussion of Prof. Luan in this laboratory during experiments are greatly acknowledged. This research is supported by CNSF 59778019 and 29807004.

\section{REFERENCES}

AWWA Research Committee on Coagulation. (1989) Committee report: coagulation as integrated water treatment process. J. Amer. Water Works Assoc. 81(10), 72 .

Bottero J. Y. (1990) Coagulation and Flocculation. AWWA Research Foundation, Denver, CO 80235.

Bottero J., Poirier J. and Fiessinger F. (1981) Studies of partially neutralized aqueous aluminum chloride solutions: indentification of aluminum species and relation between the composition of the solutions and their efficiency as a coagulant. Water Sci. Technol. 13(1), 601.

Bottero J. Y., Tchoubar D. and Arnaud M. (1991) Partial hydrolysis of ferric chloride salt. Structural investigation by dynamic light scattering and small-angle X-ray scattering. Langmuir 7(5), 1365-1369.

Cardile C. M. (1989) Tetrahedral $\mathrm{Fe}^{3+}$ in ferrihydrite: ${ }^{57} \mathrm{Fe}$ Mössbauer spectroscopy evidence. Clays Clay Miner. 36(6), 537-539.

Combes J. M., Manceau A., Calas G. and Bottero J. Y. (1989) Formation of ferric oxides from aqueous solutions: a polyhedral approach by X-ray absorption spectroscopy: I. Hydrolysis and formation of ferric gels. Geochim. Cosmochim. Acta 53, 583-594.

Dempsey B. A., Ganho R. and O'Melia C. R. (1984) The coagulation of humic substances by means of aluminum salts. J. Amer. Water Works Assoc. 76(4), 141.

Dentel S. K. (1991) Coagulation control in water treatment. CRC Crit. Rev. Environ. Control 21, 41-135.
Duan J. M. (1997) Influence of dissolved silica on flocculation of kaolin suspensions with hydrolyzed metal salts. Doctoral Dissertation, UCL, London.

Furrer G., Ludwig C. and Schindler P. W. (1992) On the chemistry of the Keggin $\mathrm{Al}_{13}$ polymer. J. Colloid Interface Sci. 149, 56.

Gray K. A., Yao C. H. and O’Melia C. R. (1995) J. Amer. Water Works Assoc. 87(4), 136-146.

Gregory J. (1973) Rate of flocculation of latex particles by cationic polymers. J. Colloid Interface Sci. 42, 448-456.

Hsu P. H. and Cao D. (1990) Effect of acidity and hydroxylamine on the determination of aluminum with ferron. Soil Sci. 152(3), 210-219.

Iler R. K. (1979) The Chemistry of Silica. Wiley, New York. Jullien R. and Bottet R. (1987) Aggregation and Fratal Aggregation. World Scientific, Singapore.

Khoe G. H. and Robins R. G. (1989) Polymerization reactions in hydrolyzed iron(III) solutions. J. Colloid Interface Sci. 133(1), 244-252.

LePrince A., Fiessinger F. and Bottero J. Y. (1984) Polymerized iron chloride: an improved inorganic coagulant. J. Amer. Water Works Assoc. 76, 93-97.

Letterman R. D., Tabatabaie M. and Ames Jr. R. S. (1979) The effect of bicarbonate ion concentration on flocculation with aluminum sulfate. J. Amer. Water Works Assoc. 71(8), 467-472.

Letterman R. D. and Vanderbrook S. G. (1983) Effect of solution chemistry on coagulation with hydrolyzed Al(III). Water Res. 17, 195.

Lewis, T. E. Ed. (1989) The Environmental Chemistry and Toxicology of Aluminum. Lewis Publishers Inc, Chelsea, MI.

Melikov I. V. (1987) Kinetics of hydroxide Fe(III) solid phase formation. J. Colloid Interface Sci. 117, 1-9.

Martin R. B. (1991) $\mathrm{Fe}^{3+}$ and $\mathrm{Al}^{3+}$ hydrolysis equilibrium: cooperative in $\mathrm{Al}^{3+}$ hydrolysis reactions. J. Inorg. Biochem. 44, 141-147.

Mikami, Yanayi, Molita and Tonaiyama (1980) The coagulation property and application of polyferric sulfate. PPM 5, 24-32 (in Japanese).

Parathasarathy N. and Buffle J. (1985) Study of polymeric aluminum(III) hydroxide solutions for application in wastewater treatment. Water Res. 19(1), 25-36.

Tang H. X. and Stumm W. (1987) The coagulation behavior of $\mathrm{Fe}(\mathrm{III})$ polymer species. I, II. Water Res. 21(1), $115-121,122-128$.

Tang H. X. (1990) Basic researches on inorganic polymer flocculant. Environ. Chem. 10, 1-12 (in Chinese).

Tang H. X., Tian B. Z., Luan Z. K. and Zhang Y. (1994) Inorganic polymer flocculant polyferric chloride, its properties, efficiency and production. In Chemical Water and Wastewater Treatment, Vol. III, eds R. Klute and H. H. Hahn pp. 57-69. Springer, Berlin.

Tang H. X. and Luan Z. K. (1996) The difference of behavior and mechanism between pre-polymeric inorganic flocculants and traditional coagulant. In Chemical Water and Wastewater Treatment (IV), eds H. H. Hahn, E. Hoffman and H. Odegaard. Springer, Berlin.

Tchoubar D., Bottero J. Y., Quienne P. and Arnaud M. (1991) Partial hydrolysis of ferric chloride salt. Structural investigation by photon-correlation spectroscopy and small-angle X-ray scattering. Langmuir 7, 398.

Tian B. Z. and Tang H. X. (1989) Speciation of polyferric chloride solutions by ferron method. Environ. Chem. 8(4), 8 (in Chinese).

Wang D. S., Tang H. X. and Cao F. C. (2000) Particle speciation analysis of inorganic polymer flocculants: an investigation by PCS. Colloids Surf. 166, 27-32.

Van Benschoten J. E. and Edzwald J. K. (1990a) Chemical aspects of coagulation using aluminum salts. I. Hydrolytic reactions of aluminum and polyaluminum chloride. Water Res. 24(12), 1519. 
Van Benschoten J. E. and Edzwald J. K. (1990b) Chemical aspects of coagulation using aluminum salts. II. Coagulation of humic substances using aluminum and polyaluminum chloride. Water Res. 24(12), 1527.
Van der Woude J. H. A. and De Bruyn P. L. (1983) Formation of colloidal dispersions from supersaturated iron(III) nitrate solutions. I. Precipitation of amorphous iron hydroxide. Colloids Surf. 8, 55. 